\title{
Salinomycin's potential to eliminate glioblastoma stem cells and treat glioblastoma multiforme (Review)
}

\author{
JUSTIN W. MAGRATH and YONGHYUN KIM \\ Department of Chemical and Biological Engineering, The University of Alabama, Tuscaloosa, AL 35487-0203, USA
}

Received May 8, 2017; Accepted July 12, 2017

DOI: $10.3892 /$ ijo.2017.4082

\begin{abstract}
Glioblastoma multiforme (GBM) is the most common and deadliest form of primary brain tumor. Despite treatment with surgery, radiotherapy, and chemotherapy with the drug temozolomide, the expected survival after diagnosis remains low. The median survival is only 14.6 months and the two-year survival is a mere $30 \%$. One reason for this is the heterogeneity of GBM including the presence of glioblastoma cancer stem cells (GSCs). GSCs are a subset of cells with the unique ability to proliferate, differentiate, and create tumors. GSCs are resistant to chemotherapy and radiation and thought to play an important role in recurrence. In order to effectively treat GBM, a drug must be identified that can kill GSCs. The ionophore salinomycin has been shown to kill cancer stem cells and is therefore a promising future treatment for GBM. This study focuses on salinomycin's potential to treat GBM including its ability to reduce the CSC population, its toxicity to normal brain cells, its mechanism of action, and its potential for combination treatment.
\end{abstract}

\section{Contents}

1. Introduction

2. Salinomycin's effect on GSCs

3. Normal neural cell toxicity

4. Salinomycin's effect on CSC stemness

5. Mechanism of action on GBM

6. Combination therapy

7. Conclusion

\section{Introduction}

Glioblastoma multiforme (GBM) is the most common and deadliest form of primary brain tumor. While current standard

Correspondence to: Professor Yonghyun Kim, Department of Chemical and Biological Engineering, The University of Alabama, Box 870203, Tuscaloosa, AL 35487-0203, USA

E-mail: ykim@eng.ua.edu

Key words: salinomycin, cancer stem cells, glioblastoma treatment includes a rigorous regimen of surgery, radiotherapy, and chemotherapy with temozolomide, its effectiveness remains low. The median survival rate for the condition is only 14.6 months and the two-year survival rate is a mere $30 \%(1,2)$. Temozolomide is the only FDA-approved chemotherapy for primary GBM, highlighting the need for better drugs to improve patient outcomes. One possible reason for this observed treatment resistance is the heterogeneity of GBM. Studies have shown that many types of cancers including GBM contain a subpopulation of cells known as cancer stem cells (CSCs) (3-6). CSCs are the only cells that have the ability to proliferate, differentiate, and generate tumors. Because of this, they are important to recurrence and metastasis. CSCs have also been found resistant to radiation and chemotherapy $(7,8)$. Investigations on the susceptibility of glioblastoma cancer stem cells (GSCs) to temozolomide have conflicting results, with some finding depletion and others, enrichment (9-13). These studies have also found a variety of genetic factors that prevent temozolomide effectiveness on GBM including the methylation status of the $\mathrm{O}(6)$-methylguanine-DNA-methyltransferase (MGMT) promoter, p53 mutations, and ATP-binding cassette (ABC) transporters. In order to effectively treat glioblastoma, a drug must be identified that can target GSCs and overcome these mechanisms of resistance.

One emerging drug for targeting GSCs is salinomycin. Salinomycin is an ionophore with a preference for $\mathrm{Na}^{+}$and $\mathrm{K}^{+}$ that was isolated from Streptomyces albus (14). Salinomycin has antimicrobial activity and has been used since the 1980 s as a coccidiostat and growth promoter (15-18). It was not until a 2009 study by Gupta et al that salinomycin's selectivity for CSCs was elucidated (19). In this study, 16,000 compounds were screened for their ability to kill breast cancer stem-like cells created by the knockout of CDH1 with shRNA. This cell population displayed all of the primary CSC characteristics including tumorsphere formation, chemoresistance, CSC marker expression, and tumor seeding ability. Salinomycin was found to kill these cells with a greater than 10 -fold lower $\mathrm{IC}_{50}$ as compared to the non-knockout population and reduce tumor seeding ability in mice by 100 -fold. Since this initial identification of salinomycin as having CSC potency, researchers have discovered effectiveness against numerous other types of cancer stem cells including chronic lymphocytic leukemia, prostate cancer, colorectal cancer, and lung adenocarcinoma (20-24). Furthermore, unlike temozolomide, salinomycin has been shown to act independently of p53 and 
is able to overcome ABC transporters $(25,26)$. Salinomycin's mechanism of action however remains to be clearly identified. While some researchers have found evidence of apoptosis, others have indicated autophagy, and still others have identified the mechanism as controlled necrosis (25-28). This study focuses on salinomycin's potential to treat GBM including its ability to reduce the CSC population, its toxicity to normal brain cells, its mechanism of action, and its potential for combination treatment.

\section{Salinomycin's effect on GSCs}

There are a variety of methods to test the effect of salinomycin on GSCs. One method is comparing the potency of salinomycin on cells that are enriched for GSCs to those that are not. In 2015, Chen et al grew the GL261 GBM line in both GSC-enriching neurosphere culture and differentiationinducing adherent culture (29). They found the neurosphere culture cells to be much more sensitive to salinomycin than the adherent culture cells, suggesting an increased toxicity in GSCs. Using similar logic, Xipell et al determined the viability of 18 different cell lines when treated with salinomycin (30). They compared the $\mathrm{IC}_{50}$ values of the neurosphere cultures and adherent cultures and found the neurosphere cultures had significantly lower $\mathrm{IC}_{50}$ dosages.

Another method to measure stemness is by determining the ability of cells to form neurospheres in vitro. This is known as a clonogenicity assay and has been conducted on salinomycin treated GBM in studies by Chen et al in 2015 , Qin et al in 2015, and Xipell et al in 2016 (27,29,30). The ability to form neurospheres is a mark of stemness, so inhibiting this ability is evidence of a drug that targets GSCs. Chen et al and Qin et al both demonstrated salinomycin's ability to decrease clonogenicity (27,29). Furthermore, Xipell et al tested multiple salinomycin concentrations finding a dose-dependent decrease in neurosphere formation (30).

A final criterion that has been employed to test the effect of salinomycin on GSCs is gene expression. A variety of markers have been used to identify GSCs including CD133, SOX2, Nestin, and Musashi-1 (5,31-33). However, only one study has investigated the effect of salinomycin on these GSC markers. Xipell et al used qRT-PCR to show that an unspecified concentration of salinomycin resulted in decreased express of the GSC markers Musashi, Sox2, and Nestin in one cell line (30).

Together these three indicators provide evidence of salinomycin's ability to kill GSCs. In order to confirm this hypothesis though, more data are needed. GSC marker gene expression should be repeated with additional cell lines. The effect of salinomycin on GSC markers should also be assessed using alternative methods such as flow cytometry and western blotting. Most importantly, salinomycin's ability to reduce GBM tumor seeding ability in mice should be assessed as it was for breast cancer in Gupta et al (19).

\section{Normal neural cell toxicity}

A potentially significant limitation to the use of salinomycin for killing GSCs is its toxicity to normal neural cells. An outbreak of toxic polyneuropathy in cats occurred in the

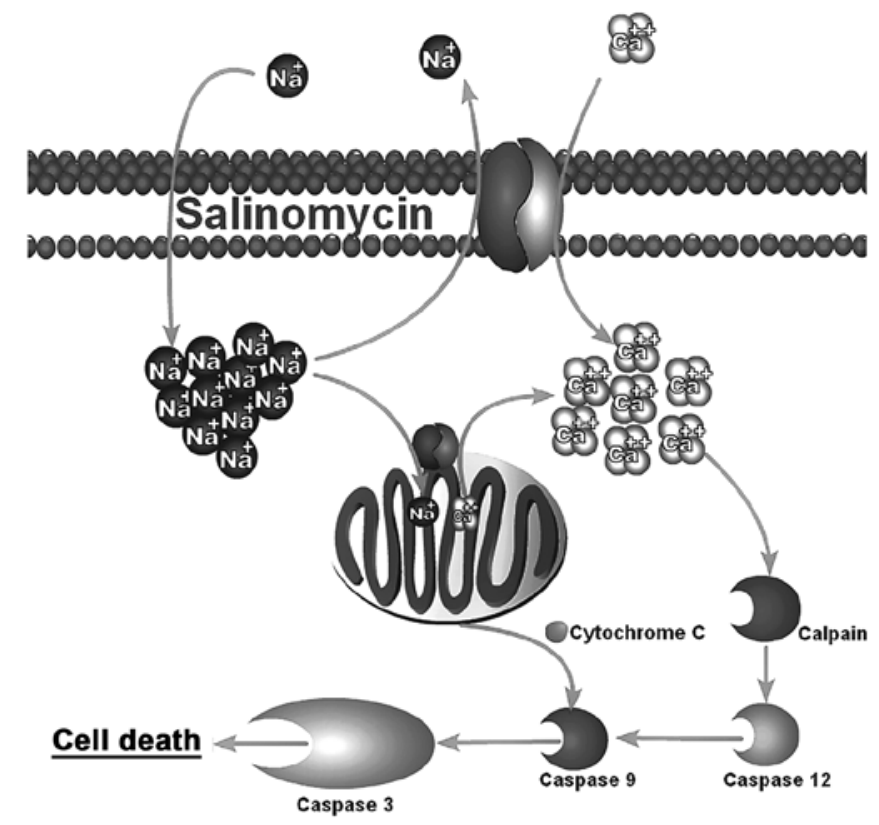

Figure 1. Summary of salinomycin's mechanism of action on neurons Salinomycin transports $\mathrm{Na}^{+}$into the cell, causing the plasma membrane and mitochondrial NCXs to work in reverse leading to an increase in cytosolic $\mathrm{Ca}^{2+}$. Elevated intracellular $\mathrm{Ca}^{2+}$ levels activate calpain, which in turn activates the caspase pathway. Cytochrome $c$ released from the depolarized mitochondria also activates caspase-9. Caspase-activation results in cell death via apoptosis (38). Reprinted with permission from Nature (72).

Netherlands in 1996 as a result of cat food contaminated with salinomycin at a level of 13-21 ppm (34). Of the estimated 100,000 exposed cats, 823 developed acute paralysis which began in the hindlimbs and then, for some cats, progressed to the forelimbs. Morphological findings included loss of axons and Schwann cell swelling. Salinomycin toxicity has also been identified in dogs, horses, and even humans (35-37). In 2004, a 35-year-old man working in a factory making animal feed accidentally inhaled/ingested an estimated $1 \mathrm{mg} / \mathrm{kg}$ body weight of salinomycin. He developed nausea, shortness of breath, and dizziness within minutes and complained of leg weakness once arriving at the hospital. The patient subsequently developed rhabdomyolysis and was not able to be discharged until 40 days after exposure (37).

In 2011, Boehmerle et al investigated this neural cell toxicity using dorsal root ganglia neurons and Schwann cells from mice (38). They found significant viability reductions in both cell types when treated with salinomycin. They discovered this death was occurring via apoptosis and is a result of salinomycin's action as a sodium ionophore. Salinomycin causes an upregulation of intracellular sodium which subsequently causes an intracellular calcium upregulation due to reversal of the $\mathrm{Na}^{+} / \mathrm{Ca}^{2+}$ exchangers (39). This intracellular calcium influx then leads to calpain and cytochrome $c$-mediated apoptosis (38). This mechanism is shown in Fig. 1.

In order for salinomycin to be utilized as a clinically effective treatment against GBM, salinomycin must either 1) be more sensitive to calcium induced apoptosis than normal cells or 2) act through a different mechanism that is specific to cancer cells. In the former case, a dosage high enough to kill GSCs but low enough to prevent neurotoxicity could be 
Table I. Evidence for the three different cell death pathways.

\begin{tabular}{lllll}
\hline & & \multicolumn{2}{c}{ Number of studies } & \\
Cell death pathways & \multicolumn{1}{c}{ Evidence } & Yes & No & \multirow{2}{*}{ Refs. } \\
\hline Apoptosis & Annexin V/PI Increase & 2 & 2 & $(27,29,30,62)$ \\
& Caspase-3 cleavage & 2 & 3 & $(27,29,30,62,63)$ \\
\multirow{3}{*}{ Autophagy } & Increased caspase-3 activity & 1 & 1 & $(27,30)$ \\
\multirow{2}{*}{ Programmed necrosis } & p62 accumulation & 2 & 0 & $(30,63)$ \\
& LC3-II upregulation & 2 & 0 & $(30,63)$ \\
& ROS increase & 3 & 0 & $(27,30,63)$ \\
& Mitochondrial PTP opening & 3 & 0 & $(27,30,62)$ \\
\hline
\end{tabular}

used to selectively kill GSCs without harming normal cells. This potential selectivity may be due to the presence of a greater concentration of $\mathrm{Na}^{+} / \mathrm{Ca}^{2+}$ exchangers or a higher than normal intracellular calcium concentration in GSCs. Calcium is a secondary messenger in the Wnt pathway which has been found to be expressed in GBM, providing a possible explanation $(40,41)$. If this is not the case, salinomycin may act through a different, GSC-specific mechanism. Under this scenario, salinomycin could be used as an effective treatment whether or not the salinomycin concentration required to kill GSCs is less than the concentration which kills normal cells. In the case where the required salinomycin dose is low, salinomycin alone would be effective in killing GSCs without causing normal cell toxicity. However, if the salinomycin dose required to eliminate GSCs is similar to that causing normal cell toxicity, salinomycin could be administered along with a $\mathrm{Na}^{+} / \mathrm{Ca}^{2+}$ exchanger inhibitor. This inhibitor would prevent salinomycin induced apoptosis of normal neural cells while allowing salinomycin to kill GSC through GSC-specific mechanisms. Therefore, understanding salinomycin's mechanism of action is of great importance to understanding salinomycin's safety and potential for clinical application.

\section{Salinomycin's effect on CSC stemness}

Studies on other types of cancer have demonstrated salinomycin can overcome many characteristics that make CSCs difficult to treat. ABC transporters export many drugs out of the cell, thus decreasing their intracellular concentration and potency $(42,43)$. This allows CSCs to survive many commonly administered chemotherapy agents. However, Fuchs et al discovered salinomycin is able to overcome these transporters and remain effective against leukemia stem cells (25). Another important CSC characteristic is invasiveness. CSCs are believed to play an important role in metastasis, the deadliest cancer progression. Multiple researchers have shown salinomycin decreases CSC invasiveness and migration (44-47). This physiologic change is associated with the FAK-ERK1/2 signaling pathway in liver CSCs (44) and the abolition of STAT3 and STAT1 interactions in colorectal CSCs (45). Salinomycin has also been shown to differentiate CSCs, transforming them from their chemoresistant and tumorogenic state to a state that can be eliminated by common chemotherapeutics $(46,48)$. While it is not known exactly how salinomycin modulates these CSC characteristics, numerous studies have shown the drug interferes with the Wnt, Notch, and Hedgehog signally pathways, all of which are important for CSC maintenance (20,49-52).

\section{Mechanism of action on GBM}

The three primary regulated cell death pathways are apoptosis, autophagic cell death, and necrosis $(53,54)$. Apoptosis can be triggered either extrinsically or intrinsically and results in the activation of caspase-enzymes that breakdown the cell in a controlled manner that does not negatively impact the surrounding tissue (54-56). Autophagy on the other hand, is a pathway that can have pro-survival or pro-death effects $(54,57,58)$. Autophagy can degrade organelles to provide energy for the cell, but over activation can lead to cell death. Necrosis is thought to be a more uncontrolled cell death which causes the release of cell contents into the extracellular environment leading to inflammation. However, recent studies have identified specific necrotic pathways leading to the idea of controlled necrosis $(54,59)$. The effect of salinomycin on indicators for these three pathways in GBM is discussed here and summarized in Table I.

Apoptosis. Evidence of salinomycin's ability to induce apoptosis has been shown for leukemia, prostate cancer, breast cancer, and ovarian cancer $(21,22,60,61)$. However, studies on GBM have not found such a consistent trend. Common methods used to assess apoptosis include Annexin V flow cytometry, procaspase- 3 cleavage via western blotting, and caspase-3/7 activity. Of the four studies that analyzed Annexin V flow cytometry, Chen et al showed a $25 \%$ positive population with salinomycin treatment, while the other three studies showed no or minimal Annexin V staining $(27,29,30,62)$. Western blot analysis of procaspase-3 cleavage was detected in Chen et al and Qin et al but not in Calzolari et al, Booth et al, or Xipell et al $(27,29,30,62,63)$. Surprisingly, the amount of pro-caspase-3 cleavage detected in Chen et al was greater for the lower salinomycin concentration, calling into questing the validity of the data. Only Qin et al and Xipell et al analyzed caspase-3/7 activity. While Qin et al found an increase in activity, Xipell et al found no difference $(27,30)$. Though, Qin et al found the cleavage of pro-caspase-3 and an increase in caspase-3/7 activity, they found apoptosis was not the primary contributor to cell death in their GBM cells. Only a 


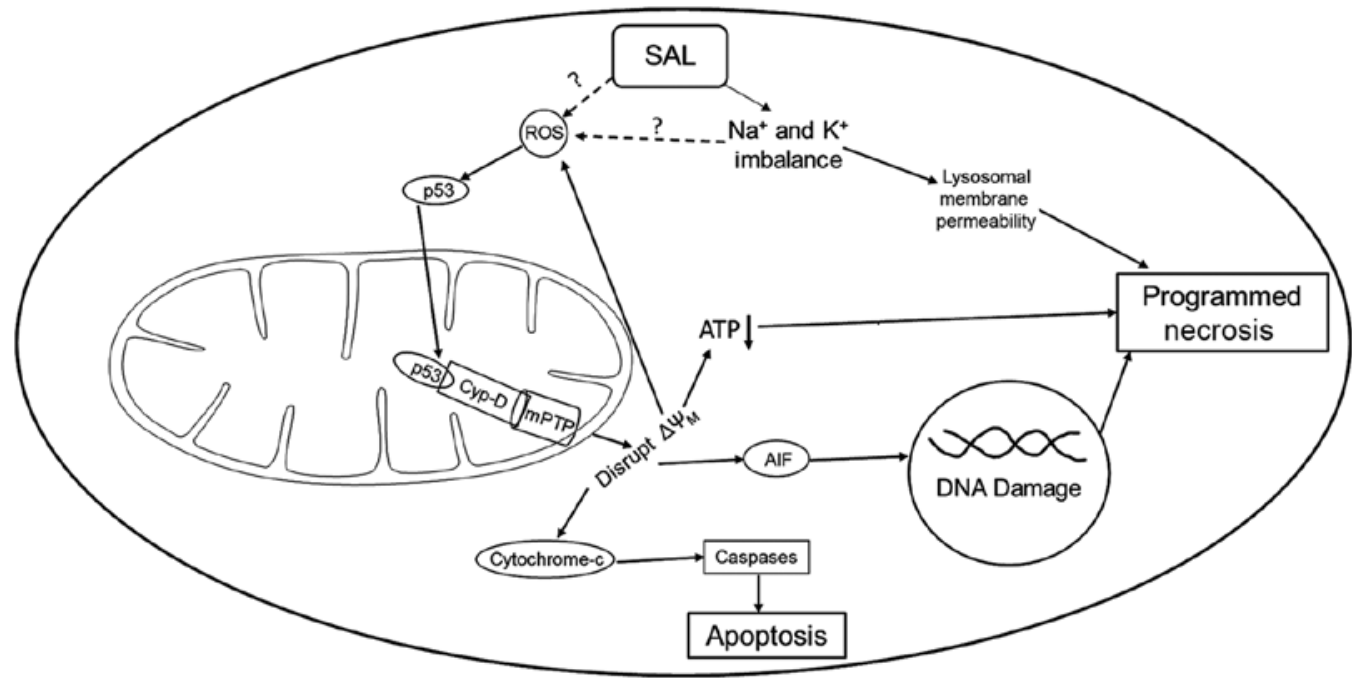

Figure 2. Summary of salinomycin's mechanism of action on GBM. Either a direct or indirect method causes ROS upregulation leading to p53 migration into the mitochondria. In the mitochondria, $\mathrm{p} 53$ forms a complex with Cyp-D to open the mitochondrial permeability transition pore, disrupting the mitochondrial membrane potential and leading to the release of cytochrome $c$ and AIF. Cytochrome $c$ activates the caspases causing apoptosis, while AIF damages DNA leading to programmed necrosis (27). The mitochondrial membrane disruption also decreases ATP production, adding another signal toward necrosis. In addition to upregulating ROS, salinomycin causes a $\mathrm{Na}^{+}$and $\mathrm{K}^{+}$imbalance which is hypothesized to interfere with lysosomal membrane permeability and also lead to programmed necrosis (30).

small part of the cell death was ameliorated using the apoptosis inhibitor zVADfmk (27). Together these data suggest apoptosis may play a role but is not the main mechanism of cell death of GBM. This is a promising conclusion for it suggests GBM are killed using a different mechanism than normal neuron and Schwann cells.

Autophagic cell death. The role of autophagy in salinomycininduced GBM death has not been investigated to as great a degree as apoptosis. The studies that have looked into it though indicate it plays some kind of role. Xipell et al found a larger number of acidic vesicles in salinomycin treated cells and confirmed this finding with transmission electron microscopy images showing an increase in autophagosomes, autolysosomes, and lysosomes (30). Biochemically, they found an increased conversion from LC3-I to LC3-II, a marker for autophagosome synthesis (64). They also, however, found increased p62 accumulation, suggesting insufficient autolysosome degradation (30). Consistent with these findings, Booth et al also found upregulation of LC3-II and p62 upon treatment with salinomycin (63). These results are similar to those obtained when GBM is treated with the autophagy inhibitor Bafilomycin A1 (30). The combination of salinomycin and Bafilomycin A1 amplified these effects (30). Lysosomal maturation was found to be decreased by salinomycin as evidence by a decrease in the amount of active cathepsin $\mathrm{B}$, which requires a low lysosomal $\mathrm{pH}$ (30). This lack of lysosomal maturation may be explained by the destabilization of Donnon potentials by salinomycin as a result of its action as an ionophore for $\mathrm{Na}^{+}$and $\mathrm{K}^{+}(30)$. Xipell et al found ROS also plays an interesting role in autophagy. The ROS inhibitor NAC (N-Acetyl-cystein) reduced p62 accumulation without affecting LC3-II upregulation in salinomycin treated cells (30). This suggests salinomycin induced ROS may be an important cause of the aberrant autophagic response.
Necrosis. While apoptosis and autophagy are affected to some degree by salinomycin, the most compelling studies point to necrosis as the predominant mechanism of salinomycin induced GBM death. Xipell et al found salinomycin results in three of the most common executioners of necrosis: low levels of intracellular ATP, lysosome membrane permeability, and osmotic swelling (30). Qin et al showed a high salinomycin concentration causes over $40 \%$ of cells to stain positive for PI but not Annexin V, indicating necrotic cell death (27). Furthermore, Qin et al found the general necrosis inhibitor Necrostatin-1 was able to prevent most of the salinomycininduced necrosis and viability reduction (27). The combination of Necrostatin-1 and the apoptosis inhibitor zVADfmk eliminated virtually all salinomycin-induced death suggesting necrosis and apoptosis are both active in salinomycin-induced cell death with necrosis playing the larger role.

Though specific necrosis pathways are still being understood, Vaseva et al identified a necrosis pathway in 2012 involving p53 opening of the mitochondrial permeability transition pore (mPTP), known as the mitochondrial permeability transition-driven regulated cell death pathway (MPT-driven RCD) (53,65-67). In this pathway, an increase in reactive oxygen species (ROS) causes unphosphorylated p53 to migrate into the mitochondrial matrix where it binds with cyclophilin D (Cyp-D, PPID) forming a p53-CypD complex. This complex stimulates mPTP opening causing a loss in the mitochondrial membrane potential and the release of cytochrome $c$ and apoptosis-inducing factor, leading to necrosis. Three studies investigating salinomycin and GBM have discovered that salinomycin increases $\operatorname{ROS}(27,30,63)$ and three studies (two overlapping) have also found that salinomycin causes a deterioration of the mitochondrial membrane potential $(27,30,62)$. Unlike the inconsistency of the apoptosis indicators, there are no studies that suggest salinomycin does not increase ROS or interfere with the 
mitochondrial membrane potential. Qin et al demonstrated in a step-wise manner that salinomycin-induced necrosis proceeds through the same necrotic pathway as identified by Vaseva et al $(27,65)$. By knocking out and then overexpressing Cyp-D, they showed its necessity for salinomycin-induced necrosis. Knockdown of p53 also prevented cell death and the formation of the p53-CypD complex identified using western blot. ROS inhibition with $\mathrm{N}$-acetyl-L-cysteine reduced p53 translocation into the mitochondria as well as mPTP opening, indicating the importance of ROS in this pathway (27). The details of this mechanism are shown in Fig. 2.

From an analysis of the current research on salinomycin's effect against GBM, MTP-driven RCD appears to be the primary mechanism of action with a small amount of death attributed to apoptosis. This is a different mechanism than the calcium-induced apoptosis that kills neurons and Schwann cells, providing support for potential therapeutic applications in the future (38). However, two important questions remain: 1) how does salinomycin's structure or action as an ionophore lead to ROS and 2) why is salinomycin selective to GBM over normal tissue and GSCs specifically?

\section{Combination therapy}

Combination therapy is a method that can potentially be used to reduce the concentration of salinomycin required. This can help prevent the neuron and Schwann cell toxicity caused by higher doses of the drug. Delwar et al used salinomycin in combination with the alkylating chemotherapy agents temozolomide (TMZ), carmustine (BCNU), and lomustine (CCNU) in a two-phase treatment approach (68). Cells were treated with one of the alkylating agents for three weeks and then with a low concentration of salinomycin or vehicle control for ten weeks. While the cells in the wells treated with vehicle control remained alive and were able to regrow, the number of surviving cells was drastically reduced in the wells treated with salinomycin. Only $21 \%$ of TMZ/salinomycin treated wells contained any live cells, suggesting combination therapy with TMZ and salinomycin as a promising treatment for prolonging patient survival (68).

Tumor necrosis factor-related apoptosis-inducing ligand (TRAIL) and valproate have also been found effective against GBM in combination with salinomycin $(62,63)$. TRAIL is a protein that binds to TRAIL receptor I or II in order to induce apoptosis, usually in tumor cells $(69,70)$. Calzolari et al showed that combination of salinomycin and TRAIL resulted in 5-10\% GBM viability while salinomycin alone resulted in $70 \%$ viability (62). The combination therapy leads to apoptotic death indicated by Annexin V/PI flow cytometry and pro-caspase-3 cleavage. Interestingly, the apoptosis inhibitor zVAD was able to prevent the significant viability reduction in only one of the three cell lines examined. Salinomycin was found to upregulate TRAIL-R2 leading to the increased potency of the combination (62). Valproate is a histone deacetylase inhibitor commonly used to treat epilepsy and bipolar disorder (71). When combined with valproate, only a low salinomycin concentration was required to induce significant cell death (63). Valproate reduced the autophagic effects caused by salinomycin, preventing LC3-II and p62 accumulation. The combination resulted in an upregulation of ROS, the suppression of which reduced cell death (63). Overexpression of the caspase- 8 inhibitor c-FLIP-s and knockdown of the death receptor CD95 both significantly reduced the combination's toxicity (63). The ability of TRAIL and valproate to increase salinomycin's toxicity will allow a lower dose of salinomycin to be used, leading to potential clinical benefits.

\section{Conclusion}

Glioblastoma multiforme is the most common and deadliest form of primary brain tumor. It is heterogeneous in nature, containing a subpopulation of cells known as GSCs which are resistant to chemotherapy and radiation $(1,2)$. In order to effectively treat GBM, these cells must be eliminated. Salinomycin has shown efficacy in treating other types of cancer stem cells and the studies that have been conducted on GBM have shown signs of GSC depletion including a greater sensitivity of GSC-enriched cultures $(29,30)$, decreased neurosphere formation $(27,29,30)$, and decreased GSC markers detection via qRT-PCR (30). However, this evidence is insufficient to prove that salinomycin targets GSCs. To confirm this hypothesis, future research should look more extensively at the effect of salinomycin on protein and gene expression as well as examine the tumor-seeding ability of salinomycin-treated cells.

It is not only important that salinomycin can kill GSCs, but also that it does not harm normal neural cells. Neural toxicity has been shown in cats, dogs and even humans in case studies $(34,36,37)$. In 2011, Boehmerle et al demonstrated that this mechanism of death is through the calcium-induced apoptotic pathway and can be prevented by $\mathrm{Na}^{+} / \mathrm{Ca}^{2+}$ exchanger (NCX) inhibitors (38). In order for salinomycin to still be a useful GBM treatment, GBM and GSCs specifically must either 1) be more sensitive to calcium-induced apoptosis or 2) be killed through a different, GSC-specific, mechanism. This review found that salinomycin likely acts through a GSC-specific mechanism, with most death caused by MPT-driven RCD, with apoptosis playing a lesser role. To confirm this hypothesis, GBM NCXs should be either inhibited or knocked out and salinomycin toxicity determined. If salinomycin is able to still kill GSCs in the absence of working NCXs, then combination treatment with salinomycin and an NCX inhibitor is a promising future treatment regimen for GBM. Salinomycin would kill GSCs specifically via MPT-driven RCD while the NCX inhibitor would prevent salinomycin from harming normal neurons through the calcium-induced apoptotic pathway.

\section{Acknowledgements}

This material is based upon work supported by the National Science Foundation under grant no. 1604677.

\section{References}

1. Stupp R, Mason WP, van den Bent MJ, Weller M, Fisher B, Taphoorn MJ, Belanger K, Brandes AA, Marosi C, Bogdahn U, et al; European Organisation for Research and Treatment of Cancer Brain Tumor and Radiotherapy Groups; National Cancer Institute of Canada Clinical Trials Group: Radiotherapy plus concomitant and adjuvant temozolomide for glioblastoma. $\mathrm{N}$ Engl J Med 352: 987-996, 2005. 
2. Arvold ND and Reardon DA: Treatment options and outcomes for glioblastoma in the elderly patient. Clin Interv Aging 9: 357-367, 2014.

3. Bonnet D and Dick JE: Human acute myeloid leukemia is organized as a hierarchy that originates from a primitive hematopoietic cell. Nat Med 3: 730-737, 1997.

4. Singh SK, Clarke ID, Terasaki M, Bonn VE, Hawkins C, Squire J and Dirks PB: Identification of a cancer stem cell in human brain tumors. Cancer Res 63: 5821-5828, 2003.

5. Singh SK, Hawkins C, Clarke ID, Squire JA, Bayani J, Hide T, Henkelman RM, Cusimano MD and Dirks PB: Identification of human brain tumour initiating cells. Nature 432: 396-401, 2004

6. Galli R, Binda E, Orfanelli U, Cipelletti B, Gritti A, De Vitis S, Fiocco R, Foroni C, Dimeco F and Vescovi A: Isolation and characterization of tumorigenic, stem-like neural precursors from human glioblastoma. Cancer Res 64: 7011-7021, 2004.

7. Bao S, Wu Q, McLendon RE, Hao Y, Shi Q, Hjelmeland AB, Dewhirst MW, Bigner DD and Rich JN: Glioma stem cells promote radioresistance by preferential activation of the DNA damage response. Nature 444: 756-760, 2006.

8. Kim Y, Joo KM, Jin J and Nam DH: Cancer stem cells and their mechanism of chemo-radiation resistance. Int J Stem Cells 2: 109-114, 2009.

9. Beier D, Röhrl S, Pillai DR, Schwarz S, Kunz-Schughart LA, Leukel P, Proescholdt M, Brawanski A, Bogdahn U, TrampeKieslich A, et al: Temozolomide preferentially depletes cancer stem cells in glioblastoma. Cancer Res 68: 5706-5715, 2008.

10. Mihaliak AM, Gilbert CA, Li L, Daou MC, Moser RP, Reeves A, Cochran BH and Ross AH: Clinically relevant doses of chemotherapy agents reversibly block formation of glioblastoma neurospheres. Cancer Lett 296: 168-177, 2010.

11. Ghods AJ, Irvin D, Liu G, Yuan X, Abdulkadir IR, Tunici P, Konda B, Wachsmann-Hogiu S, Black KL and Yu JS: Spheres isolated from 9L gliosarcoma rat cell line possess chemoresistant and aggressive cancer stem-like cells. Stem Cells 25: 1645-1653, 2007.

12. Eramo A, Ricci-Vitiani L, Zeuner A, Pallini R, Lotti F, Sette G, Pilozzi E, Larocca LM, Peschle C and De Maria R Chemotherapy resistance of glioblastoma stem cells. Cell Death Differ 13: 1238-1241, 2006

13. Beier D, Schulz JB and Beier CP: Chemoresistance of glioblastoma cancer stem cells - much more complex than expected. Mol Cancer 10: 128, 2011.

14. Mitani M, Yamanishi T and Miyazaki Y: Salinomycin: A new monovalent cation ionophore. Biochem Biophys Res Commun 66: 1231-1236, 1975

15. Danforth HD, Ruff MD, Reid WM and Johnson J: Anticoccidial activity of salinomycin in floor-pen experiments with broilers. Poult Sci 56: 933-938, 1977.

16. Zhou S, Wang F, Wong ET, Fonkem E, Hsieh TC, Wu JM and Wu E: Salinomycin: A novel anti-cancer agent with known anti-coccidial activities. Curr Med Chem 20: 4095-4101, 2013.

17. Callaway TR, Edrington TS, Rychlik JL, Genovese KJ, Poole TL, Jung YS, Bischoff KM, Anderson RC and Nisbet DJ: Ionophores: Their use as ruminant growth promotants and impact on food safety. Curr Issues Intest Microbiol 4: 43-51, 2003.

18. Lindemann MD, Kornegay ET, Stahly TS, Cromwell GL, Easter RA, Kerr BJ and Lucas DM: The efficacy of salinomycin as a growth promotant for swine from 9 to $97 \mathrm{~kg}$. J Anim Sci 61: $782-788,1985$.

19. Gupta PB, Onder TT, Jiang G, Tao K, Kuperwasser C, Weinberg RA and Lander ES: Identification of selective inhibitors of cancer stem cells by high-throughput screening. Cell 138: 645-659, 2009.

20. Lu D, Choi MY, Yu J, Castro JE, Kipps TJ and Carson DA: Salinomycin inhibits Wnt signaling and selectively induces apoptosis in chronic lymphocytic leukemia cells. Proc Natl Acad Sci USA 108: 13253-13257, 2011.

21. Kim KY, Yu SN, Lee SY, Chun SS, Choi YL, Park YM, Song CS, Chatterjee B and Ahn SC: Salinomycin-induced apoptosis of human prostate cancer cells due to accumulated reactive oxygen species and mitochondrial membrane depolarization. Biochem Biophys Res Commun 413: 80-86, 2011.

22. Dong TT, Zhou HM, Wang LL, Feng B, Lv B and Zheng MH: Salinomycin selectively targets ' $\mathrm{CD} 133^{+}$' cell subpopulations and decreases malignant traits in colorectal cancer lines. Ann Surg Oncol 18: 1797-1804, 2011

23. Wang Y: Effects of salinomycin on cancer stem cell in human lung adenocarcinoma A549 cells. Med Chem 7: 106-111, 2011.
24. Kim YJ, Liu Y, Li S, Rohrs J, Zhang R, Zhang X and Wang P: Co-eradication of breast cancer cells and cancer stem cells by cross-linked multilamellar liposomes enhances tumor treatment. Mol Pharm 12: 2811-2822, 2015.

25. Fuchs D, Daniel V, Sadeghi M, Opelz G and Naujokat C: Salinomycin overcomes ABC transporter-mediated multidrug and apoptosis resistance in human leukemia stem cell-like KG-1a cells. Biochem Biophys Res Commun 394: 1098-1104, 2010.

26. Fuchs D, Heinold A, Opelz G, Daniel V and Naujokat C: Salinomycin induces apoptosis and overcomes apoptosis resistance in human cancer cells. Biochem Biophys Res Commun 390: 743-749, 2009.

27. Qin LS, Jia PF,Zhang ZQ and Zhang SM: ROS-p53-cyclophilin-D signaling mediates salinomycin-induced glioma cell necrosis. J Exp Clin Cancer Res 34: 57, 2015.

28. Jangamreddy JR, Ghavami S, Grabarek J, Kratz G, Wiechec E, Fredriksson BA, Rao Pariti RK, Cieślar-Pobuda A, Panigrahi S and $Ł o s$ MJ: Salinomycin induces activation of autophagy, mitophagy and affects mitochondrial polarity: Differences between primary and cancer cells. Biochim Biophys Acta 1833: 2057-2069, 2013

29. Chen T, Yi L, Li F, Hu R, Hu S, Yin Y, Lan C, Li Z, Fu C, Cao L, et al: Salinomycin inhibits the tumor growth of glioma stem cells by selectively suppressing glioma-initiating cells. Mol Med Rep 11: 2407-2412, 2015.

30. Xipell E, Gonzalez-Huarriz M, Martinez de Irujo JJ, García-Garzón A, Lang FF, Jiang H, Fueyo J, Gomez-Manzano C and Alonso MM: Salinomycin induced ROS results in abortive autophagy and leads to regulated necrosis in glioblastoma. Oncotarget 7: 30626-30641, 2016.

31. Neradil J and Veselska R: Nestin as a marker of cancer stem cells. Cancer Sci 106: 803-811, 2015.

32. Song WS, Yang YP, Huang CS, Lu KH, Liu WH, Wu WW, Lee YY, Lo WL, Lee SD, Chen YW, et al: Sox2, a stemness gene, regulates tumor-initiating and drug-resistant properties in CD133-positive glioblastoma stem cells. J Chin Med Assoc 79: 538-545, 2016.

33. Lagadec C, Vlashi E, Frohnen P, Alhiyari Y, Chan M and Pajonk F: The RNA-binding protein Musashi-1 regulates proteasome subunit expression in breast cancer- and gliomainitiating cells. Stem Cells 32: 135-144, 2014.

34. van der Linde-Sipman JS, van den Ingh TS, van nes JJ, Verhagen H, Kersten JG, Beynen AC and Plekkringa R: Salinomycin-induced polyneuropathy in cats: Morphologic and epidemiologic data. Vet Pathol 36: 152-156, 1999.

35. Rollinson J, Taylor FG and Chesney J: Salinomycin poisoning in horses. Vet Rec 121: 126-128, 1987.

36. Novilla MN, Owen NV and Todd GC: The comparative toxicology of narasin in laboratory animals. Vet Hum Toxicol 36: 318-323, 1994.

37. Story $\mathrm{P}$ and Doube A: A case of human poisoning by salinomycin, an agricultural antibiotic. N Z Med J 117: U799, 2004

38. Boehmerle W and Endres M: Salinomycin induces calpain and cytochrome c-mediated neuronal cell death. Cell Death Dis 2: e168, 2011.

39. Lattanzio FA Jr and Pressman BC: Alterations in intracellular calcium activity and contractility of isolated perfused rabbit hearts by ionophores and adrenergic agents. Biochem Biophys Res Commun 139: 816-821, 1986.

40. Yu JM, Jun ES, Jung JS, Suh SY, Han JY, Kim JY, Kim KW and Jung JS: Role of Wnt5a in the proliferation of human glioblastoma cells. Cancer Lett 257: 172-181, 2007.

41. De A: Wnt $/ \mathrm{Ca}^{2+}$ signaling pathway: A brief overview. Acta Biochim Biophys Sin (Shanghai) 43: 745-756, 2011.

42. An Y and Ongkeko WM: ABCG2: The key to chemoresistance in cancer stem cells? Expert Opin Drug Metab Toxicol 5: 1529-1542, 2009.

43. Dean M: ABC transporters, drug resistance, and cancer stem cells. J Mammary Gland Biol Neoplasia 14: 3-9, 2009.

44. Sun J, Luo Q, Liu L, Yang X, Zhu S and Song G: Salinomycin attenuates liver cancer stem cell motility by enhancing cell stiffness and increasing F-actin formation via the FAK-ERK1/2 signalling pathway. Toxicology 384: 1-10, 2017.

45. Chung SS, Adekoya D, Enenmoh I, Clarke O, Wang P, Sarkyssian M, Wu Y and Vadgama JV: Salinomycin abolished STAT3 and STAT1 interactions and reduced telomerase activity in colorectal cancer cells. Anticancer Res 37: 445-453, 2017. 
46. Kuo SZ, Blair KJ, Rahimy E, Kiang A, Abhold E, Fan JB, Wang-Rodriguez J, Altuna X and Ongkeko WM: Salinomycin induces cell death and differentiation in head and neck squamous cell carcinoma stem cells despite activation of epithelial-mesenchymal transition and Akt. BMC Cancer 12: 556, 2012.

47. Qu H, Ma B, Yuan HF, Wang ZY, Guo SJ and Zhang J: Effect of salinomycin on metastasis and invasion of bladder cancer cell line T24. Asian Pac J Trop Med 8: 578-582, 2015.

48. Beug H: Breast cancer stem cells: Eradication by differentiation therapy? Cell 138: 623-625, 2009.

49. Klose J, Eissele J, Volz C, Schmitt S, Ritter A, Ying S, Schmidt T, Heger U, Schneider M and Ulrich A: Salinomycin inhibits metastatic colorectal cancer growth and interferes with Wnt/ $\beta$-catenin signaling in CD133(+) human colorectal cancer cells. BMC Cancer 16: 896, 2016.

50. Lu Y, Ma W, Mao J, Yu X, Hou Z, Fan S, Song B, Wang H, Li J, Kang L, et al: Salinomycin exerts anticancer effects on human breast carcinoma MCF-7 cancer stem cells via modulation of Hedgehog signaling. Chem Biol Interact 228: 100-107, 2015.

51. He M, Fu Y, Yan Y, Xiao Q, Wu H, Yao W, Zhao H, Zhao L, Jiang Q, Yu Z, et al: The Hedgehog signalling pathway mediates drug response of MCF-7 mammosphere cells in breast cancer patients. Clin Sci (Lond) 129: 809-822, 2015.

52. Takebe N, Harris PJ, Warren RQ and Ivy SP: Targeting cancer stem cells by inhibiting Wnt, Notch, and Hedgehog pathways. Nat Rev Clin Oncol 8: 97-106, 2011.

53. Galluzzi L, Bravo-San Pedro JM, Vitale I, Aaronson SA, Abrams JM, Adam D, Alnemri ES, Altucci L, Andrews D, Annicchiarico-Petruzzelli M, et al: Essential versus accessory aspects of cell death: Recommendations of the NCCD 2015. Cell Death Differ 22: 58-73, 2015

54. Ouyang L, Shi Z, Zhao S, Wang FT, Zhou TT, Liu B and Bao JK: Programmed cell death pathways in cancer: A review of apoptosis, autophagy and programmed necrosis. Cell Prolif 45 487-498, 2012.

55. Kerr JF, Wyllie AH and Currie AR: Apoptosis: A basic biological phenomenon with wide-ranging implications in tissue kinetics. Br J Cancer 26: 239-257, 1972.

56. Ghobrial IM, Witzig TE and Adjei AA: Targeting apoptosis pathways in cancer therapy. CA Cancer J Clin 55: 178-194, 2005

57. Kundu $\mathrm{M}$ and Thompson CB: Autophagy: Basic principles and relevance to disease. Annu Rev Pathol 3: 427-455, 2008.

58. White E: Deconvoluting the context-dependent role for autophagy in cancer. Nat Rev Cancer 12: 401-410, 2012.

59. Galluzzi L and Kroemer G: Necroptosis: A specialized pathway of programmed necrosis. Cell 135: 1161-1163, 2008.
60. Al Dhaheri Y, Attoub S, Arafat K, Abuqamar S, Eid A, Al Faresi N and Iratni R: Salinomycin induces apoptosis and senescence in breast cancer: Upregulation of p21, downregulation of survivin and histone $\mathrm{H} 3$ and $\mathrm{H} 4$ hyperacetylation. Biochim Biophys Acta 1830: 3121-3135, 2013

61. Kaplan F and Teksen F: Apoptotic effects of salinomycin on human ovarian cancer cell line (OVCAR-3). Tumour Biol 37: 3897-3903, 2016.

62. Calzolari A, Saulle E, De Angelis ML, Pasquini L, Boe A, Pelacchi F, Ricci-Vitiani L, Baiocchi M and Testa U: Salinomycin potentiates the cytotoxic effects of TRAIL on glioblastoma cell lines. PLoS One 9: e94438, 2014.

63. Booth L, Roberts JL, Conley A, Cruickshanks N, Ridder T, Grant S, Poklepovic A and Dent P: HDAC inhibitors enhance the lethality of low dose salinomycin in parental and stem-like GBM cells. Cancer Biol Ther 15: 305-316, 2014.

64. Klionsky DJ, Abdelmohsen K, Abe A, Abedin MJ, Abeliovich H, Acevedo Arozena A, Adachi H, Adams CM, Adams PD, Adeli K, et al: Guidelines for the use and interpretation of assays for monitoring autophagy (3rd edition). Autophagy 12: 1-222, 2016.

65. Vaseva AV, Marchenko ND, Ji K, Tsirka SE, Holzmann S and Moll UM: 533 opens the mitochondrial permeability transition pore to trigger necrosis. Cell 149: 1536-1548, 2012.

66. Bernardi P: The mitochondrial permeability transition pore: A mystery solved? Front Physiol 4: 95, 2013.

67. Szalai G, Krishnamurthy R and Hajnóczky G: Apoptosis driven by IP(3)-linked mitochondrial calcium signals. EMBO J 18: 6349-6361, 1999.

68. Delwar ZM, Avramidis D, Siden Å, Cruz M, Paulsson K and Sebastian Yakisich J: Low concentration of salinomycin prevents regrowth and partially depletes human glioma cells surviving high concentrations of alkylating agents. Clin Cancer Drugs 1: 72-77, 2014. doi: 10.2174/2212697X113019990002.

69. Wiley SR, Schooley K, Smolak PJ, Din WS, Huang CP, Nicholl JK, Sutherland GR, Smith TD, Rauch C, Smith CA, et al: Identification and characterization of a new member of the TNF family that induces apoptosis. Immunity 3: 673-682, 1995.

70. Pitti RM, Marsters SA, Ruppert S, Donahue CJ, Moore A and Ashkenazi A: Induction of apoptosis by Apo-2 ligand, a new member of the tumor necrosis factor cytokine family. J Biol Chem 271: 12687-12690, 1996.

71. Michaelis M, Doerr HW and Cinatl J Jr: Valproic acid as anti-cancer drug. Curr Pharm Des 13: 3378-3393, 2007.

72. Tığlı Aydın RS, Kaynak G and Gümüş̧derelioğlu M: Salinomycin encapsulated nanoparticles as a targeting vehicle for glioblastoma cells. J Biomed Mater Res A 104: 455-464, 2016. 